\title{
PIEDRA BLANCA GENITAL. REPORTE DE TRES CASOS
}

\section{Artículo Breve}

\author{
Luis Zaror \\ Instituto de Microbiologia Clínica, Facultad de Medicina \\ Universidad Austral de Chile. Casilla 567, Valdivia, Chile. \\ O. Fischman, Petri V., Carvalho M.T.F., Pope S., Porfirio N. \\ Disciplinas de Micología e Dermatologia, \\ Escola Paulista de Medicina, Sao Paulo, Brasil.
}

Palabras clave: Trichosporon beigelih, micosis superficial

Key word: Trichosporon beigelii, superficial mycoses

\section{RESUMEN}

Se informa de 2 casos de micosis superficiales causados por Trichosporon beigelii, observados en personal military uno en un homosexual, en Sao Paulo, Brasil.

\section{INTRODUCCION}

La piedra blanca es una micosis superficial cosmopolita, de baja frecuencia, cuyo agente es un hongo levaduriforme, el Trichosporon beigelii (Küch \& Rabenh.) Vuillemin (= T. cutaneum). Se localiza en la porción extrafolicular de los pelos de cualquier parte del cuerpo. Fischman y col. (4) reportaron en 1980 un alto número de casos en vello escrotal (25\%). Produce concreciones de mediana dureza blanco-amarillentas, irregulares, separadas o extensivas como verdaderas vainas por contiguidad, pudiendo confundirse con tricomicosis de Castellani. Experimentalmente esta micosis ha_ sido reproducida por Fischman y col. (4).

Como el hongo no provoca síntomas ni otras reacciones en el paciente, es necesario observar cuidadosamente el pelo y si es posible con lupa, lo cual no sucede de rutina en la práctica dermatológica.

Informamos de dos casos observados en personal militar y uno en un homosexual, en Sao Paulo, Brasil.

\section{MATERIAL Y METODO}

Fueron colectadas con tijeras muestras de vellos pubianos que presentaron concreciones visibles.

\section{SUMMARY}

[Genital white piedra. Report of three cases]

Its is informed of two cases of superficial mycoses originated by Trichosporon beigelii. These where observed in Army perssonel and one in homosexual in Sao Paulo, Brasil.

Los pelos fueron montados con KOH $20 \%$ y más tinta Parker 51 permanente (3).

Los cultivos fueron hechos en Agar Sabouraud dextrosado y Agar Lactrimel y se incubaron por 1015 días a $28-30^{\circ} \mathrm{C}$.

Las características macroscópicas, microscópicas y fisiologicas de los cultivos fueron estudiadas según Lodder (6).

\section{CASOS CLINICOS}

\section{CASO 1:}

Soldado brasileño, negro, presentaba vello escrotal áspero, con zonas blanco-amarillentas, con aproximadamente dos años de evolución. Tenía además una onicomicosis del pie por Trichophyton rubrum.

Se efectuó colección de muestra, examen microscópico directo y cultivo en Agar Sabouraud y Agar Lactrimel

\section{CASO 2:}

Soldado brasileño, mulato, que refiere tener el vello escrotal áspero como arenilla. No presentaba otros signos. 
CASO 3:

Hombre blanco, 28 años de edad, drogadicto, con test serológico HIV positivo, de malos hábitos higiénicos. Presentó lesiones eritemato-escamosas en región abdominal y caderas.

En region escrotal el pelo pubiano estaba agrupado o aislado, envuelto por nódulos voluminosos, observables a simple vista, blanco-grisáceos. (Foto 1)

\section{RESULTADOS}

Al examen microscópico directo de los vellos se observaron masas compactas blanco-amarillentas, irregulares formando vainas, con elementos levaduriformes y artroconidios (Foto 2).

Los cultivos mostraron colonias levaduriformes blancas, cerebroidales o plegadas.

Al examen microscópico se visualizaron los típicos artroconidios y pseudomicelio con blastoconidios en cadenas o racimos.

Las pruebas de asimilación y fermentación correspondieron a la especie Trichosporon beigelii.

\section{CONCLUSIONES}

La piedra blanca es una micosis que pasa muchas veces desapercibida o por su evolución inaparente $(4,8)$ al no presentar síntomas. En muchas ocasiones es un hallazgo casual o de laboratorio.

En el altimo tiempo se ha descrito un incremento de la presencia de Trichosporon beigelii en la piel de la región anal de homosexuales o de pacientes con SIDA, no encontrándose este hongo en el grupo control (9).

En los textos clásicos de micología se destaca su localización más frecuente en la barba y en el bigote. Nuestros hallazgos están en concordancia con los de Carneiro y col. y Fischamn y col. $(2,4)$, quienes encuentran preferentemente la localización genital.

El caso 3, llamaba la atención por el tamaño y la extensión de las concreciones, lo que se podría relacionar con su condición de inmunosuprimido. Cuando los nódulos son extensivos o confluentes por contiguidad pueden confundirse con tricomicosis de Castellani.

Teniendo en cuenta los aislamienttos de T. beigelii a partir de abscesos cerebrales, endocarditis, fungemia, otomicosis y otras localizaciones $(1,5$, 7 ), los hallazgos de este hongo deben ser interpretados cuidadosamente, ya sea en lesiones superficiales o en manifestaciones sistémicas, principalmente en inmunosuprimidos.

\section{REFERENCIAS}

1. ARNOLD A.G., GRIBBIN B., DELAVAL M., MACARTNE Y.F., SLACK M. (1981). Trichosporon capitatum causing recurrent fungal endocarditis. Thorax 36 : $478^{\prime} 480$.

2. CARNEIRO J.A., ALONSO A.M. \& ARAUJO F.A. (1973). Novos casos de piedra blanca genital. Anais brasileiros de Dermatología 48: 133-136.

3. COHEN, M.N.A. (1954). Simple procedure for staining tinea versicolor (M. furfur with fountain pen ink). J. Invest. Derm. 22: 9-10.

4. FISCHMAN, O., CAMARGO, Z.P. \& MEIRELES, M. C. A. (1980). Genital white piedra: an emerging new fungal disease? in superficial, cutaneous and subcutaneous infection. Proc. of the V Int. Conf. on the Mycoses, Sc. Pub. No 396: $70-76$.
5. GARDELlA, S., NOMDEVEU, B., BOMBI, J.A., MUÑOZ, J., PUIG, J., PUMAROLA, A., RQZMAN, C. (1985). Fatal fungemia with arthritic involvement caused by Trichosporon beigelii in a bone marrow transplant recipient. J. Infect. Dis. 151: 566

6. LODDER, J. (Ed.). The Yeast 2nd. ed. North Holland Publishing Company, Amsterdam, 1971.

7. RIVERA, R \& CANGIR A. (1975). Trichosporon sepsis and leukemia. Cáncer 36: 1106-1110.

8. SARSOTTI, P.V. Y SERAFINO, A. (1985). Un caso de piedra blanca en el vello pubiano y piel anexa. Rev. Arg. Micología 8 (2): 24-26.

9. STENDERUP, A., SCHONHEYDER, H., EBBESEN, P. \& MELBYE, M. (1986). White piedra and Trichosporon beigelii carriage in homosexual men. Journal of Medical and Veterinary Mycology 24: 401-406 


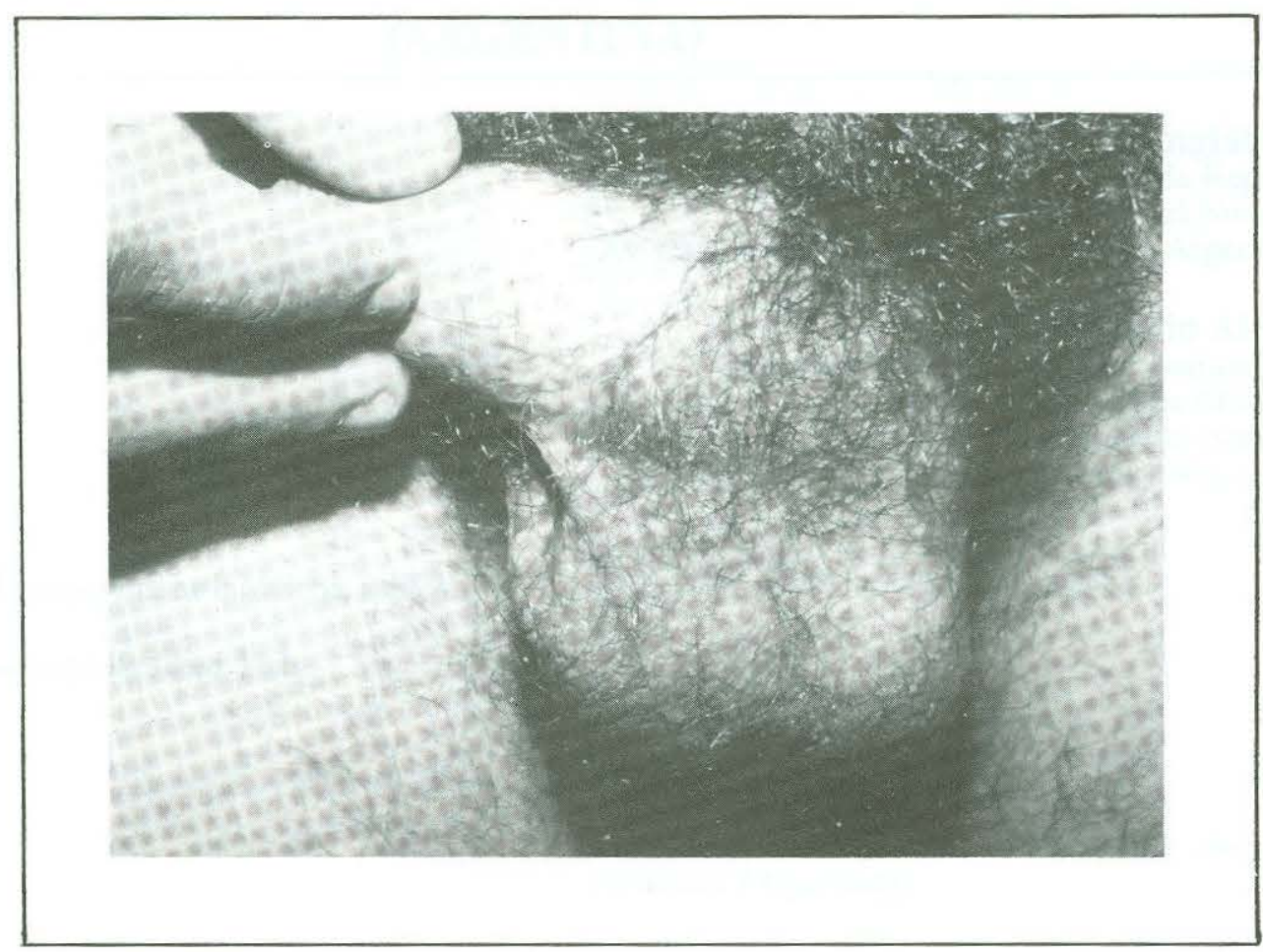

FOTO № 1

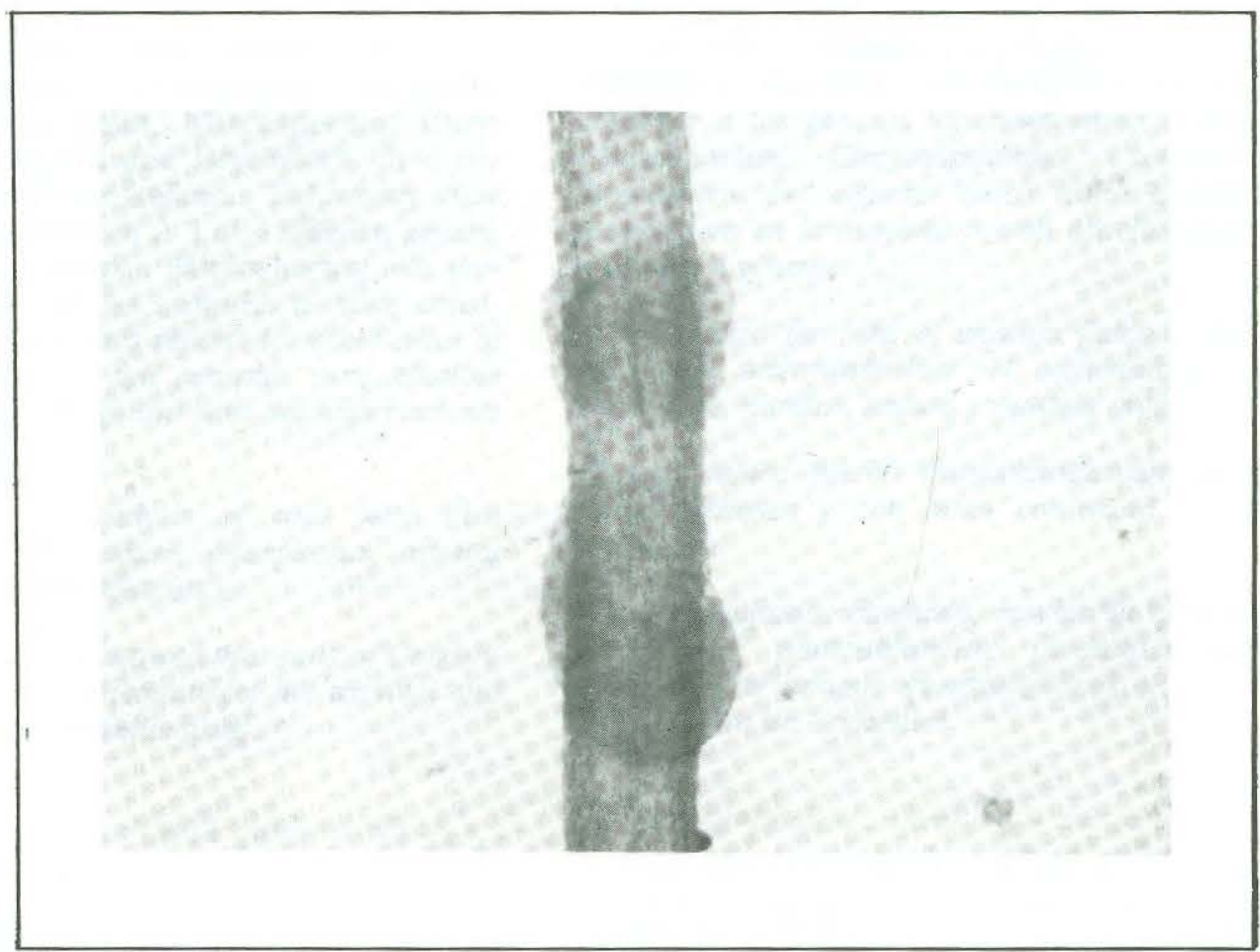

FOTO № 2 